\title{
PHẪU THUẬT NỘI SOI TOÀN Bộ KHÔNG CÓ ROBOT HỖ TRỢ, TIM ĐẬP VÁ THÔNG LIỀN NHĨ Ở 13 BỆNH NHÂN
}

\section{Đặng Quang Huy*, Lê Thị Thuy**, Nguyễn Công Hựu*, Lê Ngoc Thành*}

\section{TÓM TĂT}

Phẫu thuật nội soi toàn bộ (NSTB) đã được ứng dụng trong điều trị một số bệnh lý tim bẩm sinh. Chúng tôi báo cáo 13 trường hợp đóng thông liên nhĩ (TLN) sử dụng phương pháp NSTB không có robot hỗ trợ, tim đập. Thiết lập tuần hoàn ngoài cơ thể ngoại vi, cannula ĐM đùi trực tiếp hoặc gián tiếp; cannula $\mathrm{TMC}$ trên và dưới theo phương pháp Seldinger. Đặt 3 trocar $5 \mathrm{~mm}$ và 1 trocar $12 \mathrm{~mm}$, chỉ thắt $\mathrm{TMC}$ trên, làm đầy khoang màng phổi bằng $\mathrm{CO} 2$, tim đập trong quá trình mổ. 12 bệnh nhân TLN 1ỗ thứ phát (trong đó có 2 bệnh nhân bịt dù thất bại), 1 bệnh nhân TLN kèm tĩnh mạch phổi (TMP) lạc chỗ bán phần. Tất cả TLN được đóng bằng miếng vá nhân tạo, khâu vắt, TMP lạc chỗ được tạo đường hầm dẫn về nhĩ trái $(\mathrm{NT})$. Không có biến chứng liên quan phẫu thuật và tử vong sau mổ. Thời gian mổ và thời gian chạy máy trung bình lần lượt là 281,5 $\pm 44,9$ (phút) và 161,8 $\pm 32,7$ (phút). Bệnh nhân được rút nội khí quản trong vòng 4 giờ đầu, dẫn lưu trong ngày đầu $<80 \mathrm{ml}$. Sau 3 ngày bệnh nhân không cần dùng thuốc giảm đau và trở về với sinh hoạt bình thường sau mổ 1 tuần. Phẫu thuật NSTB vá TLN tim đập là phương pháp an toàn, người bệnh hồi phục sớm sẹo mổ có giá trị thẩm mỹ cao đặc biệt ở phụ nữ và trẻ gái.

Từ khóa: phẫu thuật tim nội soi, thông liên nhĩ, phẫu thuật tim đập, robot hỗ trợ...

\section{SUMMARY}

\section{I. ĐẠT VẤN ĐỀ}

Thông liên nhĩ (TLN) là bệnh tim bẩm sinh (TBS) thường gặp nhất, chiếm từ $6-10 \%$ tổng số các dị tật TBS. Bệnh thường diễn biến âm thầm dẫn tới suy tim, tăng áp lực động mạch phổi nặng. Hơn 20 năm trở lại đây, tim mạch can thiệp là lựa chọn hàng đầu tại hầu hết các quốc gia trên thế giới với nhiều ưu điểm [1-3]. Mặc dù vậy vẫn còn nhiều dạng TLN không bịt được dù cũng như ngày càng có nhiều báo cáo về biến chứng lâu dài của bịt dù TLN khiến bệnh nhân phải mổ lại hoặc bị đe dọa tính mạng. Phẫu thuật đóng TLN qua đường mổ cưa dọc xương ức và đường mở ngực nhỏ có nội soi hỗ trợ cho thấy còn nhiều mặt hạn chế. Trên thế giới chưa có nhiều báo cáo về mổ NSTB đóng TLN, đặc biệt ở trẻ nhỏ. Tại Việt Nam chưa có một công bố khoa học nào về việc áp dụng kỹ thuật mồ này. Chúng tôi báo cáo những kinh nghiệm ban đầu áp dụng dụng kỹ thuật NSTB sửa chữa bệnh TLN.

\section{II. ĐỐI TƯợNG VÀ PHƯƠNG PHÁP NGHIÊN CÚU}

\section{1. Đối tượng nghiên cứu}

Trong khoảng thời gian từ tháng $5 / 2016$ đến tháng 8/2016, 12 bệnh nhân TLN lỗ thứ phát đơn thuần và 1 bệnh nhân TLN kèm theo TMP lạc chỗ bán phần được lựa chọn và điều trị bằng phương pháp phẫu thuật NSTB không có robot hỗ trợ, tim đập.

Đối tượng lựa chọn bao gồm cả người lớn và trẻ nhỏ với những tiêu chuẩn lựa chọn gồm: TLN lỗ thứ phát đơn thuần, TLN kèm theo TMP lạc chỗ bán phần, TLN thể xoang tĩnh mạch, TLN kèm theo sửa VBL. Tất cả bệnh nhân được siêm âm doppler kiểm tra tình trạng động mạch chậu đùi trước mổ. Những trường hợp xơ vữa hẹp động mạch chậu đùi, kích thước động mạch đùi quá nhỏ không thiết lập được tuần hoàn ngoại vi bị loại ra khỏi nghiên cứu. Bệnh nhân TLN lỗ tiên phát hoặc TLN kèm bệnh lý khác không được lựa chọn.

\footnotetext{
* Trung tâm Tim mạch, Bệnh viện E

Ngườ chịu trách nhiệm khoa họ: GS.TS. Lê Ngoc Thành

Ngày nhận bài: 15/10/2016 - Ngày Cho Phép Đăng: 05/11/2016

Phản Biện Khoa học: PGS.TS. Đặng Ngọc Hùng
} GS.TS. Bùi Đúc Phú 


\begin{tabular}{|l|c|}
\hline $\begin{array}{l}\text { Bảng 1: } \\
\text { Các thông số nhân trắc học và thông số trước mổ }\end{array}$ \\
\hline $\begin{array}{l}\text { Tuồi (năm) } \\
\text { Giới (nam/nữ) }\end{array}$ \\
\hline Cân nặng (kg) & $3 / 10,2 \pm 9,5(4-33)$ \\
\hline $\begin{array}{l}\text { Diện tích da (m²) } \\
\text { Loại bệnh }\end{array}$ & $1,23 \pm 0,37(0,66-1,85)$ \\
\hline $\begin{array}{l}\text { TLN thứ phát } \\
\text { đơn thuần }\end{array}$ & 12 \\
\hline $\begin{array}{l}\text { TLN kèm TMP } \\
\text { lạc chỗ bán phần }\end{array}$ & \\
\hline ĐK lỗ thông (mm) & $32,6 \pm 8,4(16-43)$ \\
\hline Áp lực ĐMP (mmHg) & $44,6 \pm 7,7(31-55)$ \\
\hline Đường kính TP (mm) & $35,6 \pm 10,7(14-52)$ \\
\hline
\end{tabular}

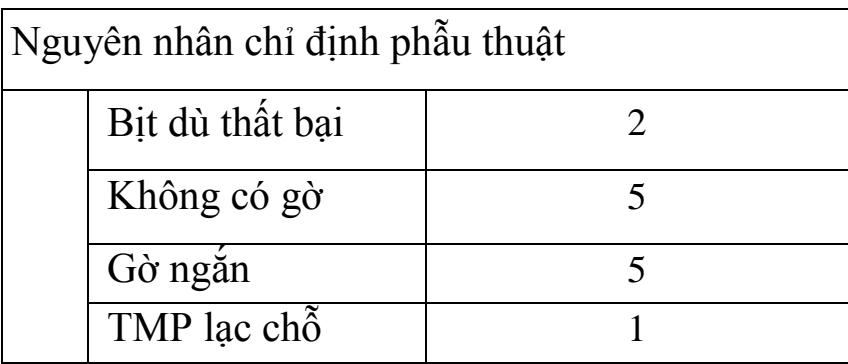

Các thông số nhân trắc học (tuổi, cân nặng, diện tích da, kích thước lỗ thông) trước mổ, các đặc điểm về bệnh học và nguyên nhân chỉ định mổ được trình bày trong Bảng 1 . Phương pháp phẫu thuật được hội đồng khoa học bệnh viện thông qua và được sự đồng thuận của gia đình bệnh nhân.

\subsection{Phương pháp phẫu thuật}

Bệnh nhân được gây mê bằng ống nội khí quản một nòng. Bác sĩ gây mê đặt catheter tĩnh mạch trung ương vào $\mathrm{TM}$ cảnh trong trái và đặt sẵn một kim luồn vào $\mathrm{TM}$ cảnh trong phải, tất cả được thực hiện vô trùng.

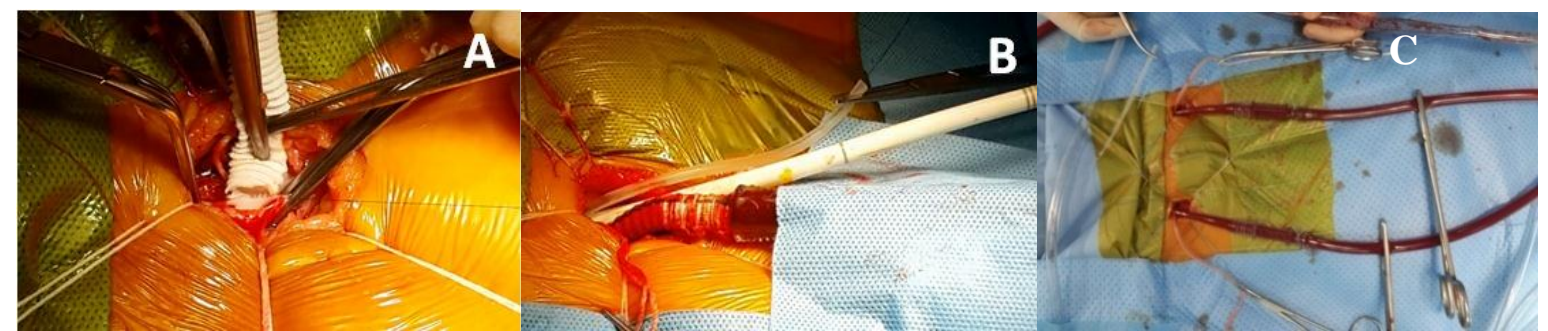

Hinh 1. (A) Cannula động mạch đùi được thiết lập gián tiếp qua một đoạn mạch nhân tạo (Dacron hoặc PTFE),

(B) TMC trên và TMC dưới được dẫn luu qua TM cảnh trong phải và TM đùi theo kỹ thuật Seldinger và (C) cannula động mạch đùi hai bên đặt trụ̂c tiếp.

Bệnh nhân được đặt tư thế nằm nghiêng trái 20-30 , hai tay xuôi theo thân người, đầu nghiêng về phía bên trái bộc lộ kim luồn đã được đặt sẵn. Phẫu thuật viên vẽ sằn vị trí dự định đặt các lỗ trocar.

Để thiết lập tuần hoàn ngoại vi chúng tôi tạo một đường rạch dài $2 \mathrm{~cm}$ ngang ở nếp bẹn bên phải, bộc lộ $Đ M$ đùi chung và $\mathrm{TM}$ đùi. Ở những bệnh nhân có cân nặng $>15 \mathrm{~kg}$, chúng tôi thiết lập đường động mạch một cách gián tiếp vào ĐM đùi chung qua một đoạn mạch nhân tạo (Dacron hoặc $\mathrm{PTFE}$ ). Cannula TMC trên và TMC dưới được đặt qua $\mathrm{TM}$ cảnh trong phải và $\mathrm{TM}$ đùi bằng phương pháp Sheldinger. Trước khi quyết định mở ngực, chúng tôi test thử đường động mạch bằng cách chạy máy thử, nếu với toàn bộ lưu lượng mà áp lực $Đ \mathrm{OM}<220 \mathrm{mmHg}$ thì chấp nhận được. Nếu áp lực đường động mạch tăng quá $220 \mathrm{mmHg}$ sẽ đặt một đường động mạch phụ đùi bên trái với kích thước cannula nhỏ hơn $4 \mathrm{~F}$ so với 
cân nặng bệnh nhân. Ở những bệnh nhân nhỏ tuổi, cân nặng $<15 \mathrm{~kg}$, chúng tôi đặt cannula trực tiếp vào ĐM đùi hai bên, chủ động lựa chọn kích thước cannula nhỏ hơn 2-4F so với cân nặng của bệnh nhân.

Đặt 4 trocar tại các vị trí đã đánh dấu sẵn, cụ thể là: 01 trocar $12 \mathrm{~mm}$ tại khoang liên sườn (KLS) $\mathrm{V}$ đường nách trước là tay làm việc chính (cho các dụng cụ: phẫu tích, kìm kẹp kim, dao điện, máy hút bỏ), 01 trocar $5 \mathrm{~mm}$ tại KLS III đường nách giữa là tay làm việc phụ (cho phẫu tích), 01 trocar $5 \mathrm{~mm}$ tại KLS V đường nách giữa (cho đèn nội soi) và 01 trocar $5 \mathrm{~mm}$ tại KLS VI đường nách giữa (cho đường hút máu về). Sau khi vào đến khoang màng phổi, hệ thống tuần hoàn ngoài cơ thể bắt đầu hoạt động, nhiệt độ thực quản được hạ dần xuống $32^{\circ} \mathrm{C}$, màng tim được mở song song và phía trước so với thần kinh hoành $1.5-2 \mathrm{~cm}$.

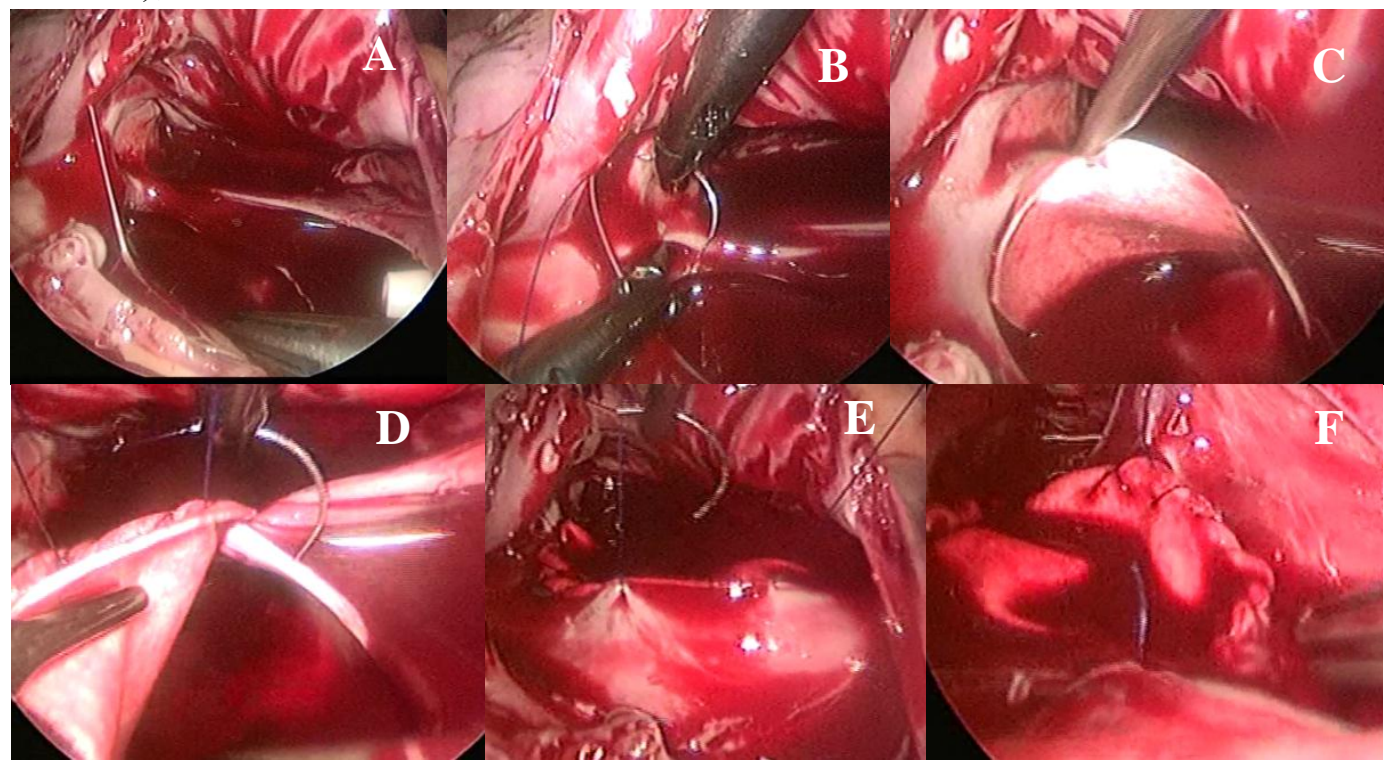

Hình 2. Kỹ thuật vá TLN NSTB. (A) Nhĩ phải được mở sau khi làm đầy khoang màng phổi và màng tim bằng CO2, lỗ TLN thứ phát (mũi tên), ống màu trắng là đầu cannula TMC duới;

$(B, C, D, E)$ quá trình vá lố TLN bằng miếng vá nhân tạo, khâu vắt;

(F) Kiểm tra miếng vá truơóc khi đóng nhĩ phải

Khoang màng phổi và màng tim được làm đầy bởi khí CO2. Mở nhĩ phải (NP) dọc theo rãnh liên nhĩ sau khi đã thắt TMC trên và bệnh nhân ở tư thế Trendelenburg. Tim đập liên tục trong suốt quá trình mổ, máu về qua xoang vành, các lỗ đổ trực tiếp trên thành $\mathrm{NP}$ và lỗ $\mathrm{TMC}$ dưới; đường hút qua trocar 4 giúp tạo phẫu trường sạch máu. Các mốc giải phẫu cần xác định trong quá trình mổ gồm: lỗ van ba lá, lỗ xoang vành, lỗ TMC dưới và các lỗ TMP phải. Tất cả lỗ thông được đóng bằng miếng vá nhân tạo, khâu vắt. TMP lạc chỗ được tạo đường hầm trong tim dẫn máu về nhĩ trái qua lỗ TLN.
Đường mở NP được đóng hai lớp. Tim được làm đầy sau khi thả thắt $\mathrm{TMC}$ trên, tư thế đầu bằng và kiểm tra cầm máu $\mathrm{kỹ}$, màng tim được đóng mũi rời. Ngừng tuần hoàn ngoài cơ thể sau khi đặt 01 dẫn lưu màng tim và 01 dẫn lưu màng phổi. Quy trình còn lại giống như phẫu thuật nội soi đơn thuần. Tất cả bệnh nhân sau mổ được kiểm tra bằng siêu âm qua thành ngực và siêu âm doppler mạch máu kiểm tra trước khi ra viện.

\subsection{Theo dõi sau mổ:}

Bệnh nhân được hẹn khám lại sau mổ 1 tháng, 3 tháng, 6 tháng. Bệnh nhân được khám, đánh giá tình trạng sẹo mổ, sự cân đối giữa hai 
ngực, tình trạng dị cảm quanh vị trí vết mổ ngực và đùi, sự hài lòng của gia đình và bệnh nhân về vị trí và kích thước sẹo mổ. Bệnh nhân được siêu âm tim qua thành ngực và siêu âm doppler mạch kiểm tra.

\subsection{Phân tích số liệu:}

Số liệu được tính ra trung bình \pm phương sai (S.D.) cho những biến định lượng và tính ra số lượng với tỉ lệ phần trăm cho những biến định tính. Số liệu được quản lý và phân tích bởi phần mềm SPSS 14.0.

\section{KẾT QUẢ}

Không có trường hợp nào tử vong trong thời gian nằm viện. Không có trường hợp nào cần mở rộng vết mổ hoặc chuyển cưa xương ức.

Tất cả bệnh nhân được thiết lập tuần hoàn ngoài cơ thể ngoại vi. Cannula ĐM được đặt gián tiếp qua một đoạn mạch Dacron ở 12 bệnh nhân ( 8 bệnh nhân trưởng thành sử dụng đoạn mạch số 8 và 4 bệnh nhân trẻ lớn $>15 \mathrm{~kg}$ sử dụng đoạn mạch số 6). Trong 4 bệnh nhân sử dụng đoạn mạch số 6,1 trường hợp trẻ nữ 10 tuổi nặng $36 \mathrm{~kg}$, sau khi chạy máy bị tăng áp lực động mạch $>220 \mathrm{mmHg}$, chúng tôi đặt thêm đương ĐM phụ bằng cannula $12 \mathrm{~F}$ trực tiếp vào $\mathrm{ĐM}$ đùi trái. Một trường hợp trẻ nữ $14,5 \mathrm{~kg}$, chúng tôi chủ động đặt trực tiếp cannula ĐM đùi hai bên. Hai trường hợp trẻ nhỏ $16 \mathrm{~kg}$ và $14,5 \mathrm{~kg}$ phải sử dụng cannula ĐM để đặt cho $\mathrm{TMC}$ dưới. Chi tiết về thiết lập tuần hoàn ngoài cơ thể được trình bày trong Bảng 2 .

\begin{tabular}{|c|c|}
\hline $\begin{array}{l}\text { Bảng 2: } \\
\text { Các thông số về thiết lập tuần hoà } \\
\text { thể ngoại vi }\end{array}$ & ngoài co \\
\hline Cannula ĐM đùi $(n=13)$ & \\
\hline Qua mạch Dacron số 8 & 8 \\
\hline Qua mạch Dacron số 6 & 3 \\
\hline $\begin{array}{l}\text { Qua mạch Dacron số } 6 \text { và } \\
\text { cannula trực tiếp ĐM đùi trái }\end{array}$ & 1 \\
\hline Cannula trực tiếp ĐM đùi hai bên & 1 \\
\hline Kích thước cannula TMC trên $(\mathrm{F})$ & $\begin{array}{l}17,4 \pm 2,8 \\
(14-21)\end{array}$ \\
\hline Kích thước cannula TMC dưới $(\mathrm{F})$ & $\begin{array}{l}19,2 \pm 2,4 \\
(15-21)\end{array}$ \\
\hline
\end{tabular}

Thời gian phẫu thuật và thời gian chạy máy trung bình cho vá TLN đơn thuần lần lượt là $275 \pm 39,9$ phút và $158,3 \pm 31,4$ phút. Tất cả bệnh nhân không cần dùng thuốc vận mạch sau ngừng hệ thống tim phổi máy và được rút máy thở trong vòng 5 giờ. Không có bệnh nhân nào có biến chứng về thần kinh sau mổ. Sau 3-4 ngày bệnh nhân không cần dùng thuốc giảm đau, người bệnh có thể trở lại sinh hoạt bình thường sau mổ 7 ngày.

Tất cả tổn thương được sửa chữa thành công. Bệnh nhân và gia đình đều rất hài lòng về hiệu quả và tính thẩm mỹ của sẹo mổ.

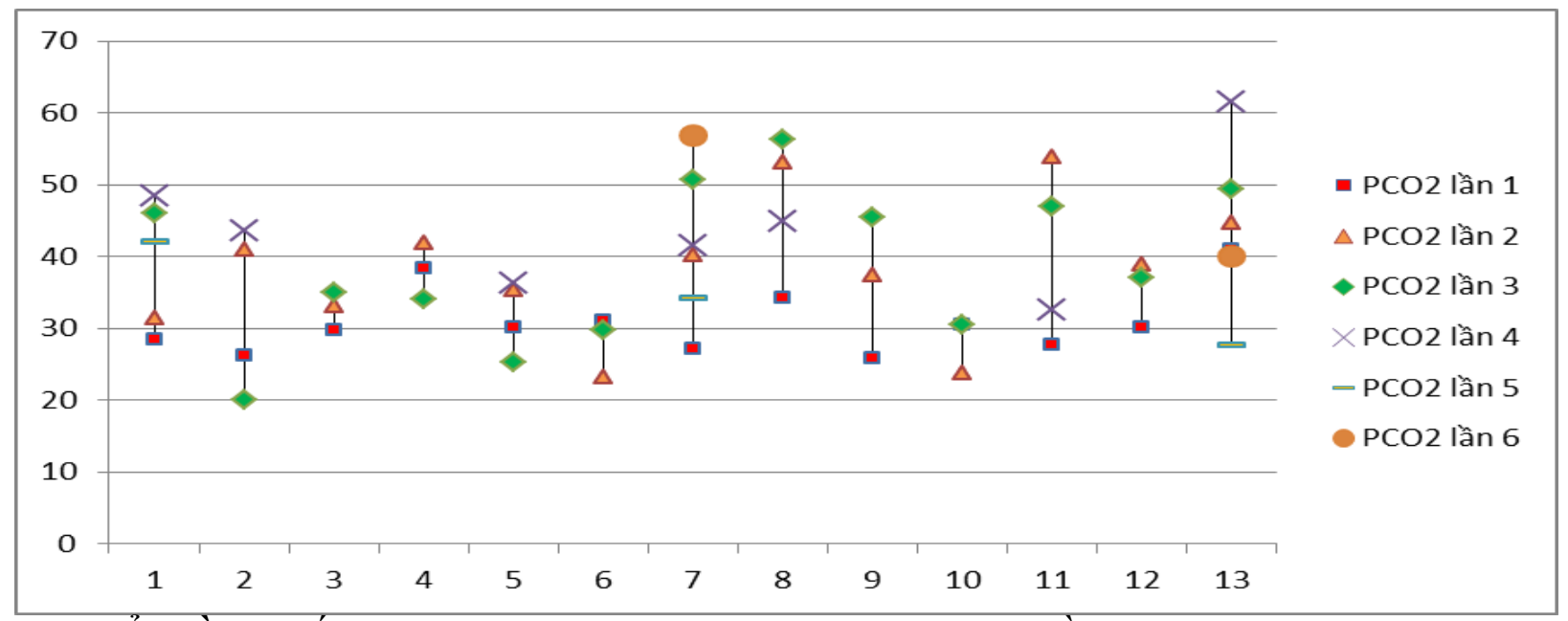

Biểu đồ 1: Biến thiên $\mathrm{PCO}_{2}$ trong máu động mạch qua các lần làm xét nghiệm khí máu 


\begin{tabular}{|c|c|c|c|}
\hline \multicolumn{4}{|c|}{ Bảng 3: Các thông số trong và sau mổ } \\
\hline & & $\begin{array}{c}\text { TLN đơn thuần } \\
(\mathrm{n}=12)\end{array}$ & $\begin{array}{l}\text { TLN kết hợp TMP } \\
\text { lạc chỗ (n=1) }\end{array}$ \\
\hline \multicolumn{4}{|l|}{ Khí máu động mạch sau mổ } \\
\hline & $\mathrm{PCO}_{2}$ & $32,58 \pm 5,7$ & 38,1 \\
\hline & Lactat & $3,62 \pm 1,67$ & 4,6 \\
\hline & $\mathrm{pH}$ & $7,47 \pm 0,042$ & 7,346 \\
\hline & Beb & $1,07 \pm 3,61$ & $-3,6$ \\
\hline \multicolumn{2}{|l|}{ Thời gian mổ (phút) } & $\begin{array}{c}275 \pm 39,9 \\
(210-330)\end{array}$ & 360 \\
\hline \multicolumn{2}{|l|}{ Thời gian chạy máy (phút) } & $\begin{array}{c}158,3 \pm 31,4 \\
(115-220)\end{array}$ & 205 \\
\hline \multicolumn{2}{|l|}{ Thời gian thở máy (giờ) } & $4,71 \pm 2,67$ & 4 \\
\hline \multicolumn{2}{|l|}{ Thời gian nằm hồi sức (giờ) } & $18,3 \pm 2,8$ & 18 \\
\hline \multicolumn{2}{|l|}{ Dẫn lưu trong 6 giờ đầu $(\mathrm{ml})$} & $39,1 \pm 28,1$ & 120 \\
\hline \multicolumn{2}{|l|}{ Dẫn lưu trong 24 giờ đầu $(\mathrm{ml})$} & $71,8 \pm 35,2$ & 150 \\
\hline \multicolumn{2}{|c|}{ Thời điểm không cần dùng thuốc giảm đau sau mổ (ngày) } & $3,3 \pm 0,5$ & 3 \\
\hline \multicolumn{2}{|l|}{ Thời gian nằm viện sau mổ (ngày) } & $8,5 \pm 2,3$ & 9 \\
\hline \multicolumn{2}{|l|}{ Biến chứng } & 0 & 0 \\
\hline
\end{tabular}

\section{BÀN LUẬN}

TLN là một trong những bệnh TBS thường gặp nhất, tỉ lệ mắc bệnh ngày càng tăng từ $0,5-$ 2,5/1000 trẻ sinh ra sống trong khoảng thời gian từ năm 1945 đến 2009 [4]. Nữ gặp nhiều hơn nam gấp 2 lần, bệnh thường phát hiện ở tuổi trưởng thành - độ tuổi đòi hỏi tính thẩm mỹ cao; do đó, nâng cao chất lượng điều trị bệnh TLN góp phần tăng hiệu quả trong công tác chăm sóc sức khỏe cộng đồng.

Ngày nay phẫu thuật tim nội soi hỗ trợ vá TLN đã được ứng dụng rộng khắp trên thế giới vì tính đơn giản, hiệu quả cao và hầu như không có tai biến. Tuy vậy người bệnh vẫn phải chịu một đường mở ngực, đau nhiều sau mổ do banh xương sườn, sẹo mổ còn dài, mất cân bằng hai ngực... Phẫu thuật NSTB có sự hỗ trợ của hệ thống robot Da Vinci ra đời khắc phục được tất cả những nhược điểm kể trên của phương pháp mổ cũ; tuy nhiên, một khó khăn rất lớn mà tất cả các bệnh viện gặp phải đó là chi phí đào tạo và chi phí cho một ca mổ rất lớn. Với sự phát triển của kỹ thuật, phẫu thuật NSTB không cần hỗ trợ của hệ thống robot Da Vinci đã đi vào thực tể song chưa được áp dụng rộng rãi.

Như chúng ta biết, phẫu thuật tim sử dụng hệ thống tim phổi máy gây tổn thương các tổ chức thông qua việc hoạt hóa pha cấp của một chuỗi các men và gây kích ứng tiểu cầu [5]. Thêm nữa, ngừng tim trong quá trình mổ gây thiếu máu cơ tim và hiện tượng tái tưới máu sau mổ [6]. Để tránh tổn thương tim do quá trình phẫu thuật, nhiều tác giả lựa chọn phẫu thuật tim đập; tuy vậy, nhiều tác giả vẫn thống nhất quan điểm rằng phẫu thuật tim đập rất ít được áp dụng cho sửa chữa các dị tật bẩm sinh và đặc biệt phẫu thuật ở trẻ nhỏ do nhiều lý do: nhiều dị tật phức tạp đòi hỏi phải bộc lộ rõ và phẫu trường nhỏ hẹp khó thao tác [5]. 

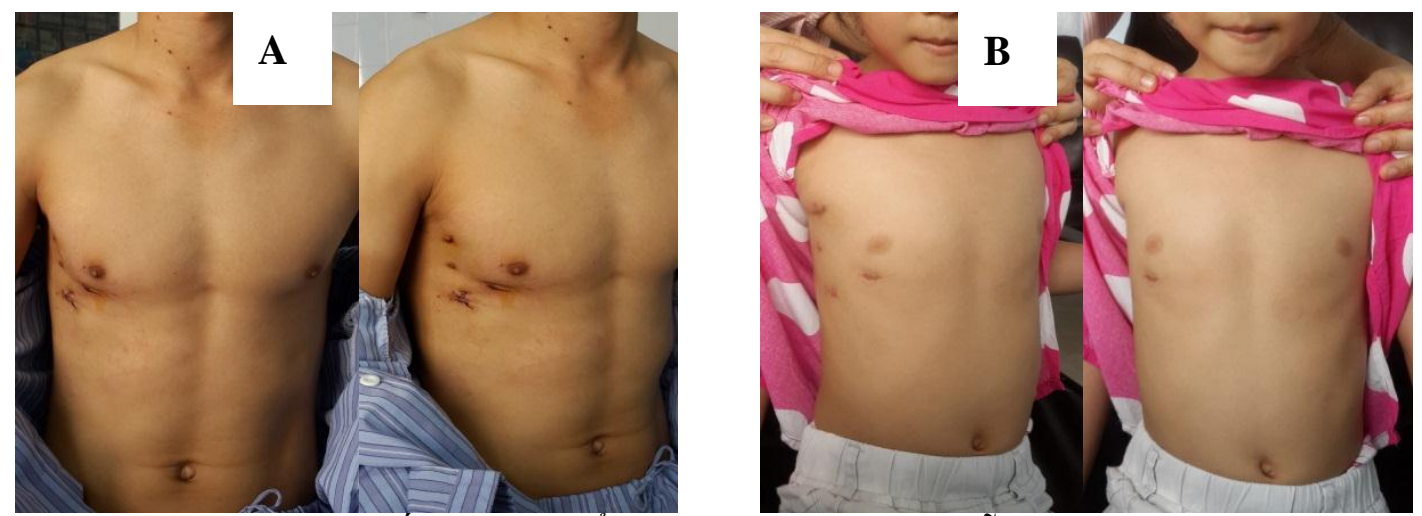

Hình 3. Kêt quả sau mố NSTB không có robot hồ trọ', tim đập.

(A) Bệnh nhân nam 24 tuổi ngay sau mổ;(B) Bệnh nhân nũ 7 tuổi sau mổ 1 tháng.

Với kinh nghiệm phẫu thuật vá TLN nội soi hỗ trợ, tim đập cho hơn 80 trường hợp, chúng tôi thực hiện vá TLN NSTB không có robot hỗ trợ, tim đập từ tháng 5/2016 với kết quả bước đầu rất tốt. Tất cả bệnh nhân được theo dõi sau ra viện 1 3 tháng. Chúng tôi đã phẫu thuật cho 5 bệnh nhân nhi và 8 bệnh nhân trưởng thành, trong đó bệnh nhân có cân nặng nhỏ nhất là $14,5 \mathrm{~kg}$. Để phẫu thuật cho những bệnh nhân nhỏ tuổi này chúng tôi đã có những thay đổi về cách thức thiết lập tuần hoàn ngoài cơ thể ngoại vi (theo Bảng 2). Thời gian mổ (từ lúc rạch da tới khi đóng da) trung bình và thời gian chạy máy trung bình lần lượt là 4-4,5 giờ và $2-2,5$ giờ. Người bệnh thở máy trung bình 4 giờ, nằm hồi sức dưới 1 ngày, lượng máu dẫn lưu sau mổ giảm hẳn so với phương pháp mổ nội soi hỗ trợ với trung bình $70 \mathrm{ml}$ trong 24 giờ đầu tiên, không bệnh nhân nào cần truyền máu sau mổ.

Thông thường với nội soi hỗ trợ, người bệnh bị hạn chế vận động tay phải trong nhiều tuần đầu sau mổ do đau và co cơ thành ngực. Với phương pháp mổ NSTB thông qua các lỗ Trocar đường kính từ $5-12 \mathrm{~mm}$ trên thành ngực người bệnh giảm đau sau mổ rất nhiều. Chúng tôi chỉ cần cho người bệnh sử dụng Morphine trong ngày đầu tại phòng hồi sức, những ngày sau tại bệnh phòng dùng giảm đau không steroid; trung bình sau ngày thứ 3 người bệnh không cần dùng thuốc giảm đau. Bệnh nhân có thể vận động tay phải bình thường sau mổ 1 tuần.
Nhiều tác giả ghi nhận xẹp phổi phải sau mổ với tỉ lệ $2,5-7,1 \%$ do thông khí một phổi trong quá trình mổ $[5,7,8]$. Chúng tôi lựa chọn thông khí hai phổi bằng nội khí quản một nòng do $40 \%$ đối tượng của chúng tôi là trẻ nhỏ, phương pháp gây mê này khiến thời gian chạy máy của chúng tôi kéo dài hơn so với việc thông khí một phồi song giúp tránh được xẹp phổi sau mổ. Mặc dù không dùng kim hút gốc ĐMC, chúng tôi không gặp biến chứng về thần kinh do làm đầy liên tục khoang màng tim và màng phổi bằng $\mathrm{CO} 2$, tốc độ bơm $\mathrm{CO} 2$ được điều chỉnh dựa trên theo dõi $\mathrm{PaCO} 2$ trong máu liên tục (biểu đồ 1). Không trường hợp nào có biến chứng mạch đùi sau mổ cũng như những thời điểm khám lại.

\section{KẾT LUẬN}

Phương pháp phẫu thuật vá TLN NSTB không có robot hỗ trợ, tim đập là phương pháp hứa hẹn có thể triển khai rộng trong tương lai gần góp phần nâng cao chất lượng điều trị bệnh tim bẩm sinh.

\section{TÀI LIỆU THAM KHẢO}

1. Alobaidan, M., et al., Successful percutaneous closure of spiral atrial septal defect. Echo Res Pract, 2015. 2(1): p. K7-9.

2. Murakami, T., et al., Transcatheter closure of atrial septal defect protects from pulmonary edema: septal occluder device gradually reduces LR shunt. Heart Vessels, 2016. 
3. Giardini, A., et al., Effect of transcatheter atrial septal defect closure in children on left ventricular diastolic function. Am J Cardiol, 2005. 95(10): p. 1255-7.

4. van der Linde, D., et al., Birth prevalence of congenital heart disease worldwide: a systematic review and meta-analysis. J Am Coll Cardiol, 2011. 58(21): p. 2241-7.

5. Ma, Z.S., et al., Totally thoracoscopic closure for atrial septal defect on perfused beating hearts. Eur J Cardiothorac Surg, 2012. 41(6): p. 1316-9.
6. Mo, A., et al., Efficacy and safety of on-pump beating heart surgery. Ann Thorac Surg, 2008. 86(6): p. 1914-8.

7. Wang, F., et al., Totally thoracoscopic surgical closure of atrial septal defect in small children. Ann Thorac Surg, 2011. 92(1): p. 200-3.

8. Liu, G., et al., Totally thoracoscopic surgery for the treatment of atrial septal defect without of the robotic Da Vinci surgical system. J Cardiothorac Surg, 2013. 8: p. 119. 